\title{
(อ) OPEN ACCESS \\ Use of ASD closure device for the sealing of false lumen entry in the ascending aorta after dissection Type A surgical repair
}

\author{
Ivo Spasov Petrov, Zoran lovan Stankov, Damyan Boychev Boychev
}

Department of Cardiology and Angiology, Acibadem City Clinic Cardiovascular Center, Sofia, Bulgaria

\section{Correspondence to}

Professor Ivo Spasov Petrov; petrovivo@hotmail.com

Accepted 23 April 2021

\section{SUMMARY}

We present a case of a persistent false lumen after ascending aorta replacement due to Stanford Type A dissection treated by endovascular means. The main entry tear was occluded with an atrial septal defect closure device, sealing the false lumen. A total of five additional stents were implanted to centralise and secure the flow in the true lumen. CT scan at 6-month follow-up showed excellent results with a decreased total aortic diameter and thrombosed false lumen.

\section{BACKGROUND}

False lumen (FL) patency after a surgical repair of Stanford Type A dissection is a common complication. The treatment options are either re-do surgery or endovascular repair. Re-do surgery is associated with higher death rates compared with an initial surgery; hence, whenever possible, endovascular treatment is preferred by many. Unfortunately, in most cases, anatomy is too complex for complete endovascular treatment in Type A persistent tears after surgery. We present a case of endovascular treatment of dissection starting from the innominate artery with the use of an atrial septal defect (ASD) occluder.

\section{CASE PRESENTATION}

A 62-year-old man presented to our clinic for the treatment of symptomatic persistent Type A dissection 6 months following aortic valve replacement and ascending aorta surgical repair, the so-called Bentall procedure. The patient was a smoker with chronic obstructive pulmonary disease, diabetes type 2, gout, obesity grade 3 and a history of hypertension grade 3 . The physical examination was

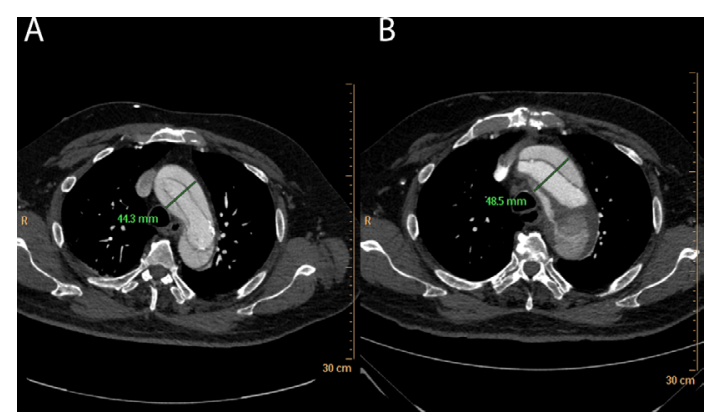

Figure 1 CTA (A) before the initial surgery and (B) 6 months after the surgery. The aortic arch had drastically increased in size. CTA, CT angiography.

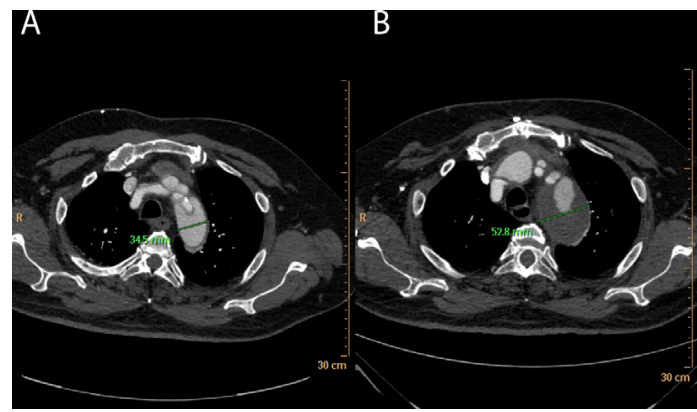

Figure 2 CTA (A) before the initial surgery and (B) 6 months after the surgery. The aortic arch had drastically increased in size. CTA, CT angiography.

unremarkable. He had palpitations, sudden weaknesses on the left side of the body and frequent headaches. The estimated Euroscore II was 14\%.

\section{INVESTIGATIONS}

On CT angiogram (CTA), patent FL was visualised starting with tear entry just proximal to the innominate artery, engaging the right common carotid artery (RCCA), left subclavian artery, superior mesenteric artery, the right common iliac artery and right common femoral artery (figures 1-5). All of the visceral branches were perfused by the true lumen except for the inferior mesenteric artery and the two right renal arteries. The FL of the RCCA was causing dynamic obstruction of the true one, which was the reason for the patient's symptoms. For the period between the initial surgical treatment and index admission, the aortic arch has dilated from $44 \mathrm{~mm}$ to $48 \mathrm{~mm}$, the supradiaphragmatic segment from $34.8 \mathrm{~mm}$ to $40.6 \mathrm{~mm}$, abdominal aorta from $32.5 \mathrm{~mm}$ to $39.4 \mathrm{~mm}$ and the infrarenal

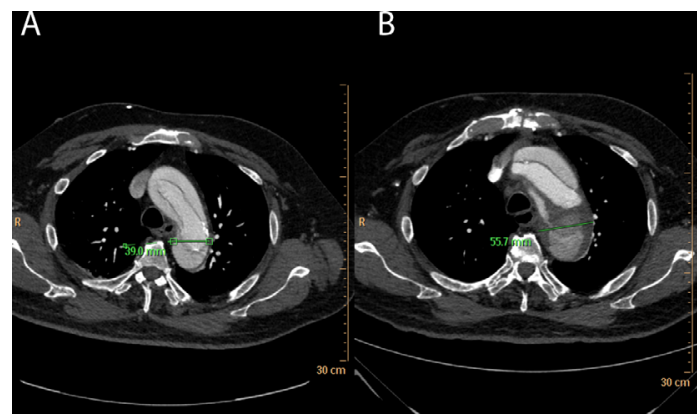

Figure 3 CTA (A) before the initial surgery and (B) 6 months after the surgery. The aortic arch had drastically increased in size. CTA, CT angiography. 


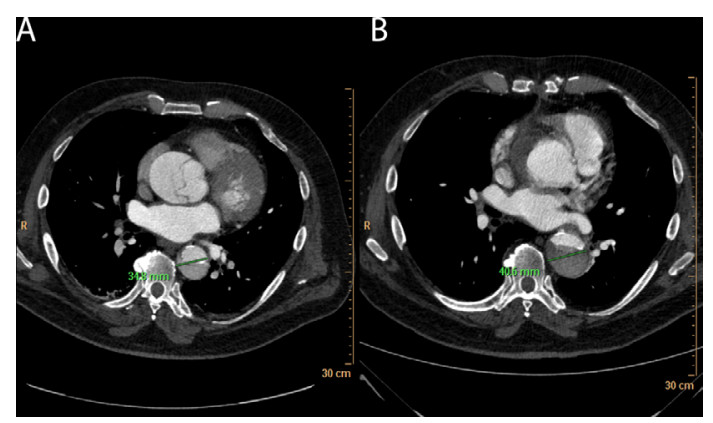

Figure 4 CTA (A) before the initial surgery and (B) 6 months after the surgery. The supradiaphragmatic aorta had increased in size by $5.8 \mathrm{~mm}$. CTA, CT angiography.

segment from $23 \mathrm{~mm}$ to $25 \mathrm{~mm}$. Considering the increasing size of the dissection, the unacceptably high operative risk and the single main entry tear, we decided to treat the patient by endovascular means.

\section{TREATMENT}

We decided to close the entry tear with ASD occluder while centralising the flow and guaranteeing the patency of the true lumen of RCCA and left subclavian artery by implanting stents. A two-step intervention was planned, first, we secured the RCCA and a month later we stented the left subclavian artery and occluded the main entry tear.

Using the right femoral approach with a $6 \mathrm{~F}$ sheath, the true lumen of RCCA was directly stented with Protégé 14/80 mm (Medtronic, USA) achieving an optimal angiographic result (figure 6).

A month later, the second stage of the intervention was performed. Initial fluoroscopy visualised the dissection tear (figure 7, video 1). Using the right brachial approach, a $5 \mathrm{~F}$ sheet pigtail catheter was placed in the true lumen of the ascending aorta. Through a left brachial approach and a 7F sheath, the left subclavian artery was cannulated. Using a 0.014" Runthrough coronary guidewire (Terumo, Japan), we passed from the true lumen of the left subclavian artery into the FL and selectively cannulated the FL of the ascending aorta. After exchanging the wire for 0.035" STORQ wire (Cordis, UK) and using the visualisation provided by the pigtail catheter in the true lumen, we passed from the FL into the true lumen with a Judkins Right diagnostic catheter at the level of the innominate artery and positioned the wire above the aortic valve prosthesis. After crossing the entry with the 7Fr delivery sheath, an ASD occluder 29ASD07 (Occlutech, Germany) was put in place and released,

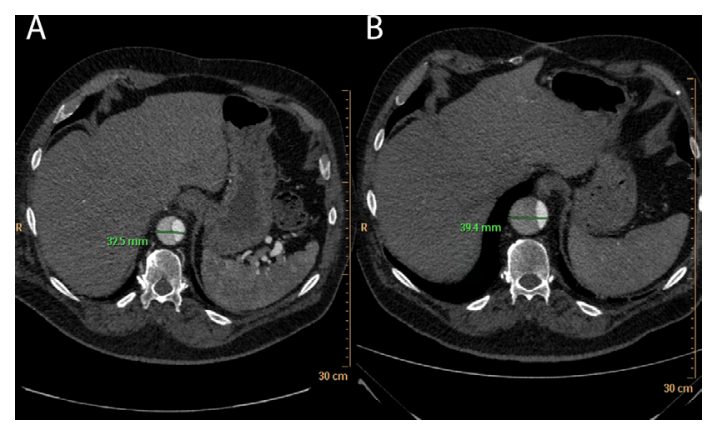

Figure 5 CTA (A) before the initial surgery and (B) 6 months after the surgery. The abdominal aorta had dilated by $6.9 \mathrm{~mm}$. CTA, CT angiography.

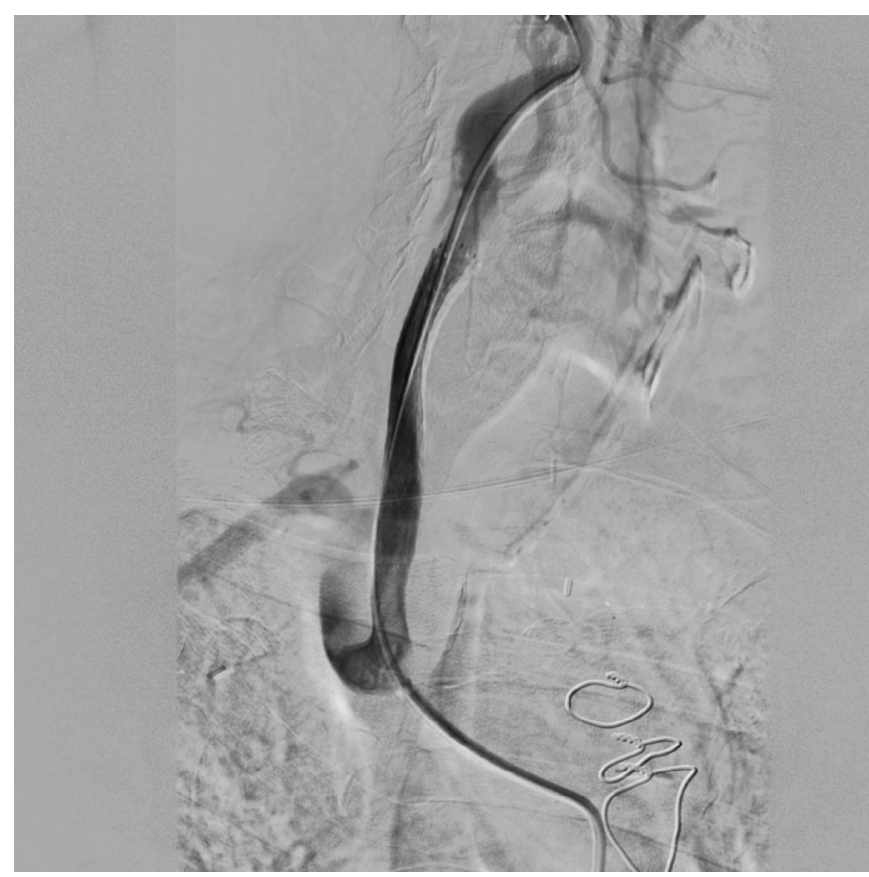

Figure 6 Stage 1 final fluoroscopy showed patent right common carotid artery with reduced size of the false lumen.

closing the entry of the FL. The first disk was released in the true lumen of the aorta and the second one in the FL, making sure the closure of the entry site is tight enough (video 2). Using the same left brachial approach, two stents were implanted in the left subclavian artery, Protégé $12 / 60 \mathrm{~mm}$ followed by Protégé $9.0 / 80 \mathrm{~mm}$ with an optimum angiographic results and securing of the true lumen. Final aortography showed no contrast in the FL (figure 7, video 3). The patient was discharged the next day without any problem.

CTA 1 month later showed persistent FL causing dynamic stenosis of the true lumen of the innominate artery; hence, we decided to perform a third intervention to stent the abovementioned arteries. Using the right femoral approach, we implanted Carotid Wallstent 7.0/40 mm (Boston Scientific, USA) covering the distal part of the Protégé and upwards and Sinus XL 20/100 mm (Optimed, Germany) in the innominate artery, covering the proximal part of the Protégé in the RCCA (figure 8).

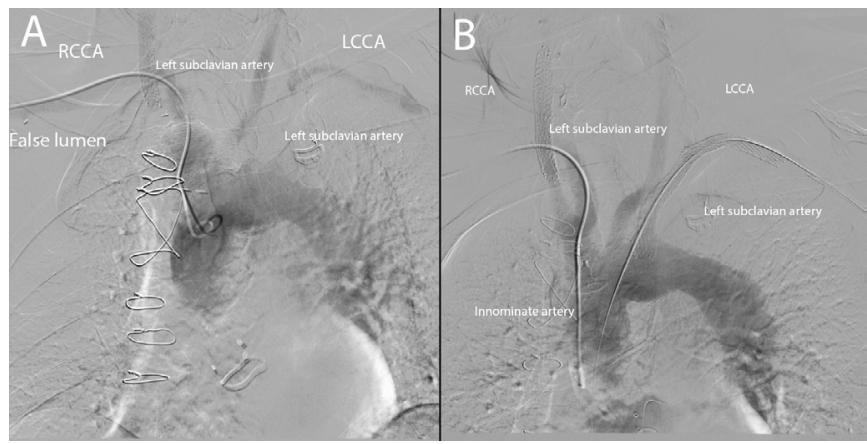

Figure 7 (A) Stage 2 initial fluoroscopy. Visualisation of the false lumen on the level of the aortic arch. (B) Stage 2 final fluoroscopy showed fully patent visceral branches and no contrast leak in the false lumen on the level of the aortic arch. ASD device was visualised occluding the dissection entry tear. ASD, atrial septal defect; LCCA, left common carotid artery; RCCA, right common carotid artery. 

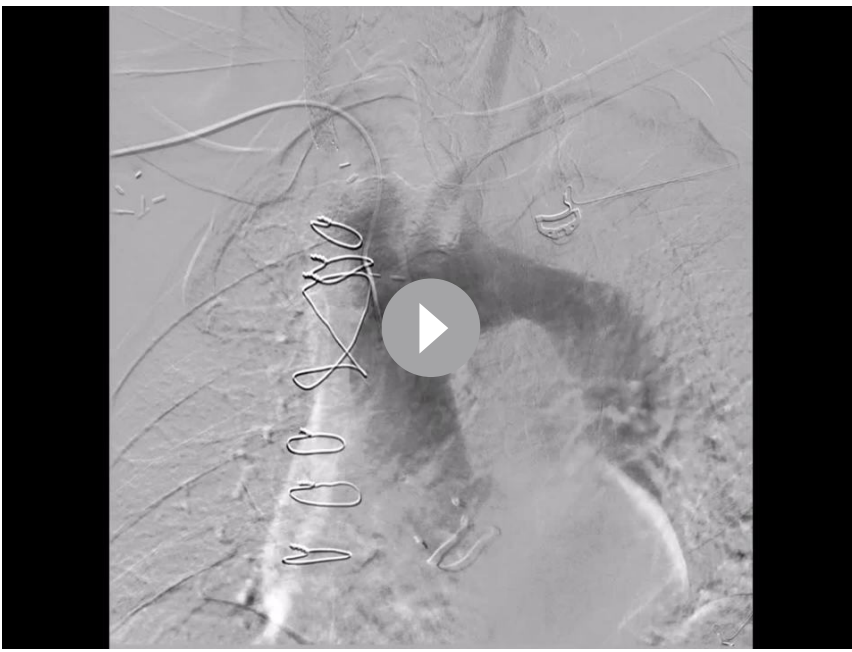

Video 1 Fluoroscopy visualising the false lumen on the level of the aortic arch.

\section{OUTCOME AND FOLLOW-UP}

A CTA 6 months after the initial procedure and 3 months after the final one showed greatly reduced flow in the FL and almost complete thrombosis of it. The para-prosthesis blood collections were greatly reduced. The aorta has shrunk in size and the true lumen had preserved and even increased its size in some places (figures 9-18). Studies show that in most patients the aorta remodelling following endovascular treatment of dissection is complete after 6 months to 1 year; hence, we expect further shrinkage of the aorta in the following months. ${ }^{12}$

\section{DISCUSSION}

FL patency in a suture site or the distal part of a replaced aorta after surgical treatment of Stanford Type A dissection is common. ${ }^{3}$ A suboptimal connection between the aorta and the implanted graft, the presence of secondary tears and suture line dehiscence may account for the patency of the FL and are leading causes of aortic enlargement and indication for re-operation (re-intervention). ${ }^{4}$

However, the re-operation mortality rate is high, with reported rates of $7.7 \%-11.1 \% .^{56}$ Thus, less invasive treatment strategies are required for correction. ${ }^{3}$ A study showed that thrombosis of

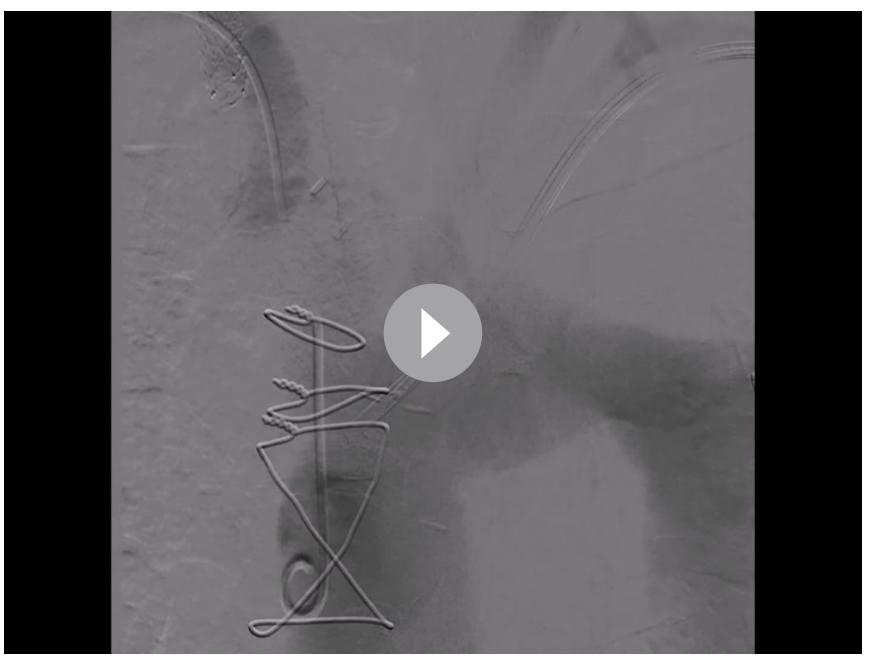

Video 2 Fluoroscopy confirming the position of the ASD occluder in the dissection tear entry. ASD, atrial septal defect.
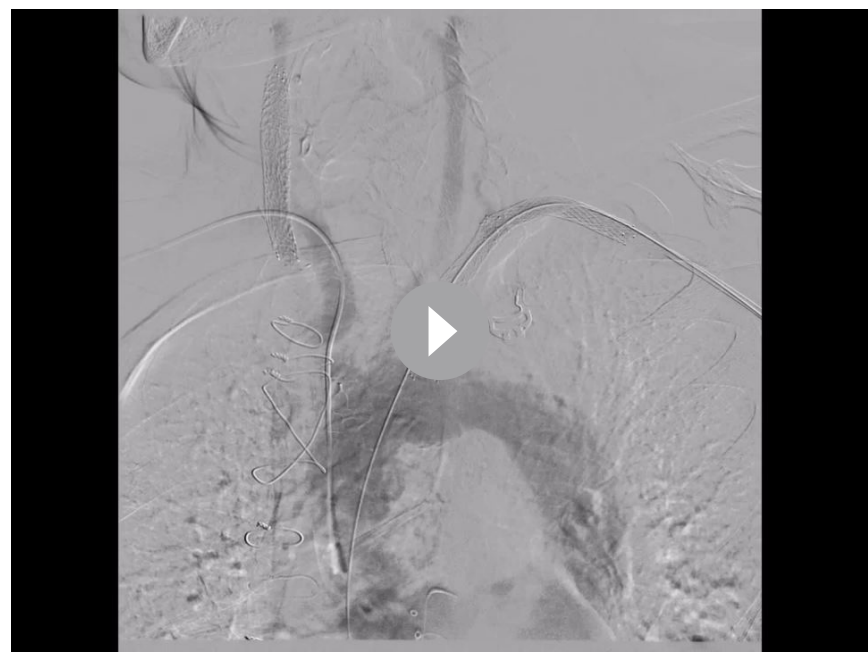

Video 3 Stage 2 final fluoroscopy visualising patent visceral arteries at the level of the aortic arch with greatly increase true lumen and isolated dissection tear by the ASD occluder. ASD, atrial septal defect.

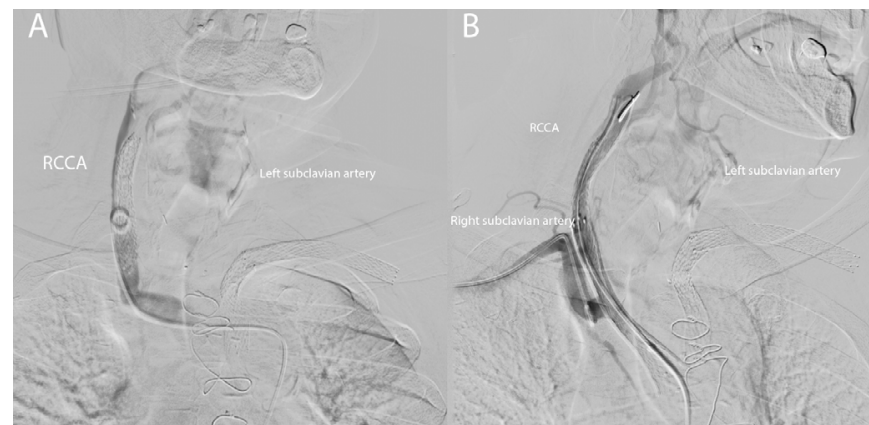

Figure 8 (A) Stage 3 initial fluoroscopy and (B) stage 3 final fluoroscopy. Stent implantation greatly reduced the size of the false lumen, secured the patency of the true lumen of RCCA and centralised the flow. RCCA, right common carotid artery.

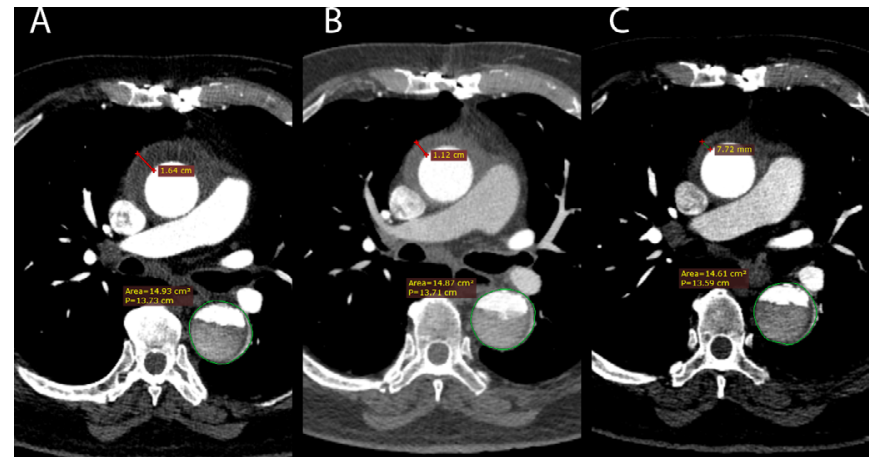

Figure 9 CTA (A) 6 months after the initial surgery, (B) 1 month after the stage 1 procedure and $(C) 3$ months after the final procedure. The para-prosthesis blood collection and the total aortic size has gradually reduced in size. CTA, CT angiography.

the FL is a predictor of better prognosis, avoiding aortic rupture and re-dissection. ${ }^{7}$

When the aortic diameter is $>5.5 \mathrm{~cm}$ or it grows $>5 \mathrm{~mm}$ per year it is a definitive indication for treatment. ${ }^{8}$ In our case, the surgical risk was high, the patient declined another open surgery and the only choice of treatment was by minimally invasive means. 


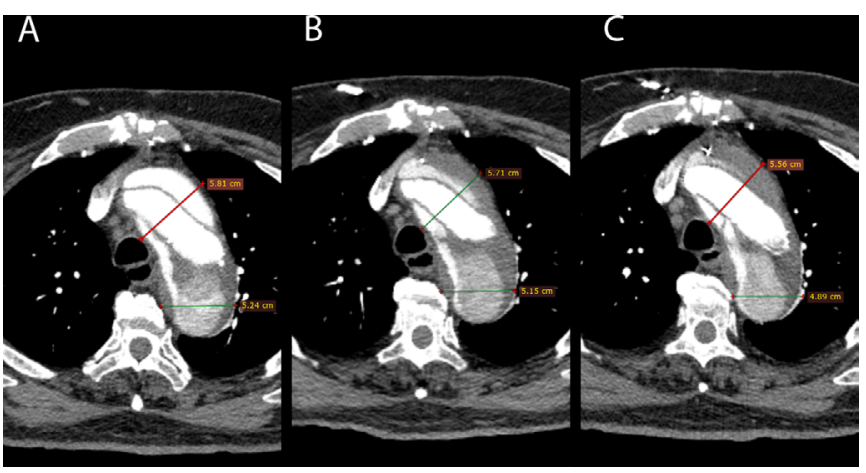

Figure 10 CTA (A) 6 months after the initial surgery, (B) 1 month after the stage 1 procedure and (C) 3 months after the final procedure. The total size of the aortic arch had reduced because of shrinkage of the false lumen. Reduced contrast leak is visualised on (B) and (C). CTA, CT angiography.

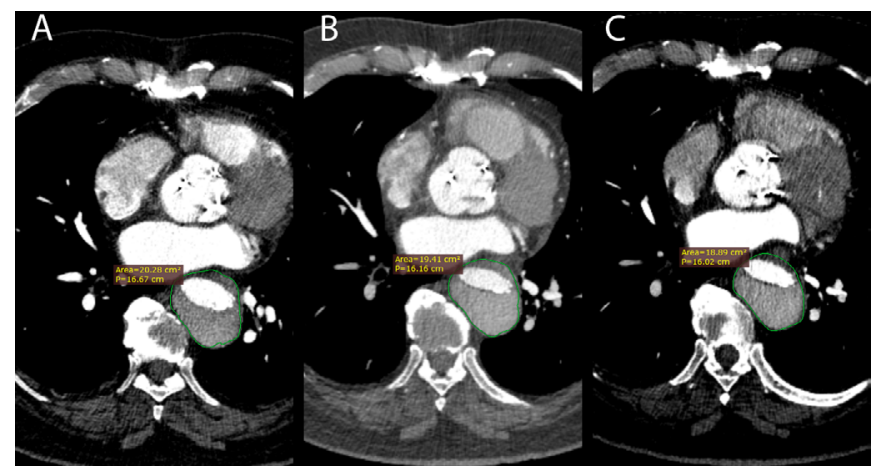

Figure 11 CTA (A) 6 months after the initial surgery, (B) 1 month after the stage 1 procedure and (C) 3 months after the final procedure. Total descending aorta size is reduced and the false lumen is thrombosed. CT, CT angiography.

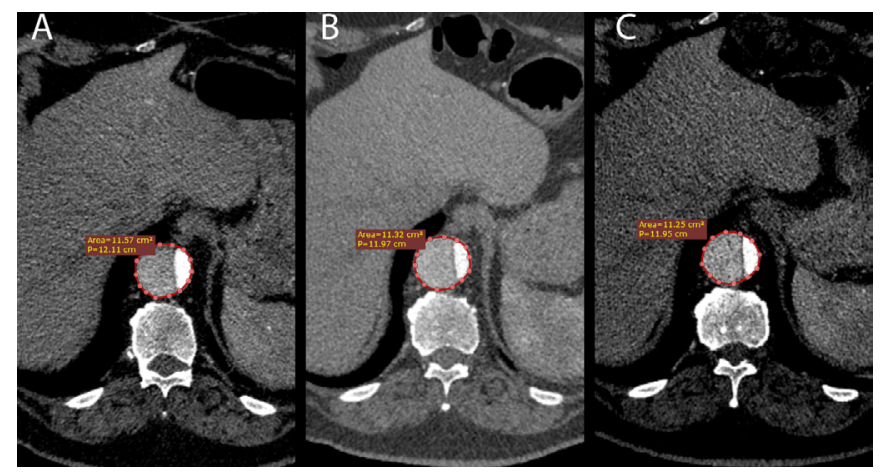

Figure 12 CTA (A) 6 months after the initial surgery, (B) 1 month after the stage 1 procedure and (C) 3 months after the final procedure. Supradiaphragmatic aorta has reduced in size and the false lumen thrombosed. CTA, CT angiography.

The entry tear was just at the innominate artery and there was no landing zone for stent-grafting. Coil embolisation was considered but the tear was neither narrow enough nor we had the security that the coils will not migrate into the innominate artery or one of its branches. The only option was the use of vascular plugs or some other type of occluder. Endovascular closure of entry tear with vascular plug in the chronic phase of a Type A dissection has been reported previously. ${ }^{39-12}$ We chose an ASD occluder because it matched the anatomy of the main tear entry.

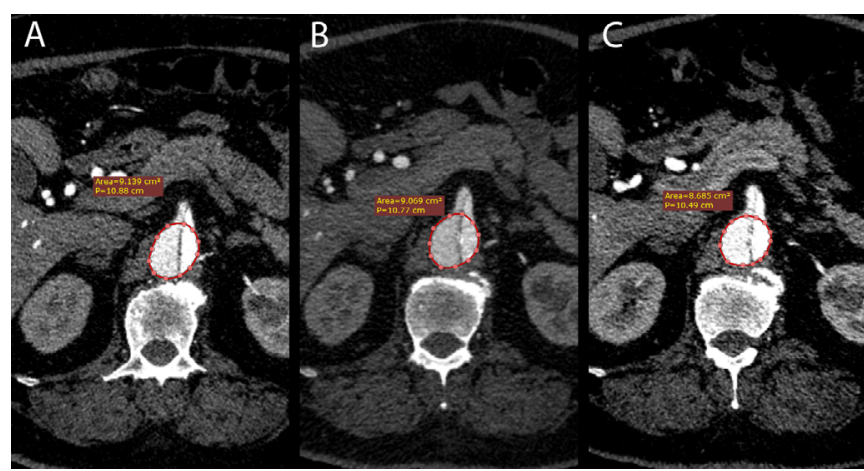

Figure 13 CTA (A) 6 months after the initial surgery, (B) 1 month after the stage 1 procedure and (C) 3 months after the final procedure. The false lumen at the level of the inferior mesenteric artery is still patent but the total aortic size is reduced. CTA, CT angiography.

There is no special approvement for the use of ASD occluder device in the aorta and it is considered as 'off-label' use. Despite that, there are numerous described cases with the off-label use of ASD occluders and vascular plugs for the treatment of cardiac and aortic pseudoaneurysms, ventricle septal defects (VSD) closure. ${ }^{13-16}$ A retrospective study involving 119 patients found that Amplatzer vascular plug and Amplatzer duct occluder I and II seem to be safe for the closure of VSD and they can be used off-label with good mid-term results. ${ }^{17}$

The orifice of the entry tear had a size of $6.8 \mathrm{~mm} \times 5.7 \mathrm{~mm}$, and the waist of the chosen device was $7.5 \mathrm{~mm}$, big enough to fit tight. The so-called left atrium disk had a diameter of $18 \mathrm{~mm}$, way bigger than the orifice of the entry tear, guaranteeing the sealing of the defect and minimising the risk of device migration. The pressure difference between the left atrium disk of the device in the high-pressure true lumen of the aorta and the right atrium disk in the lower pressure FL gave us yet another mechanism which lowered the risk of device migration.

The tissue around the entry tear should be stable enough to be able to hold the occluder in place. Dislocation of the device could have been fatal, considering the proximity to the RCCA. By approaching the entry from the FL side, the device can be sequentially deployed in an optimal position, anchoring itself in the entry hole. After deployment, the first segment of the occluder is lying flat on the true lumen intima, not obstructing the true lumen flow. 9

We stented the RCCA in advance to secure the true lumen and induce shrinkage of the FL around it before the full closure

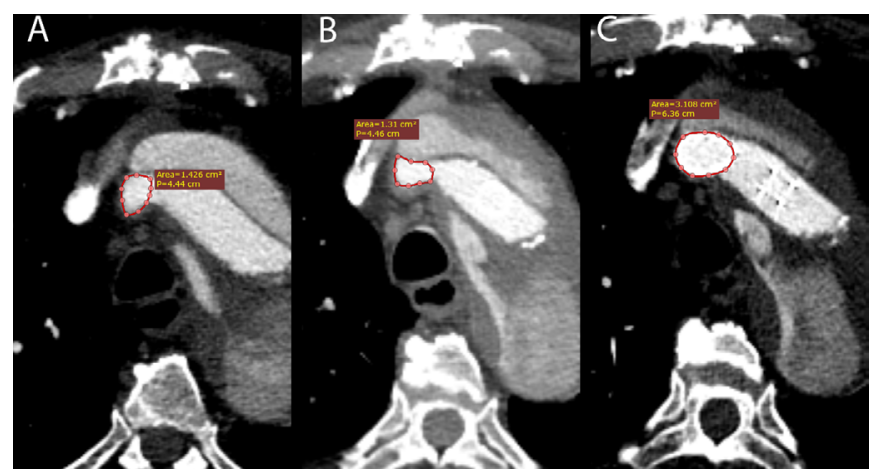

Figure 14 CTA (A) 6 months after the initial surgery, (B) 1 month after the stage 1 procedure and (C) 3 months after the final procedure. Greatly increased true lumen of the innominate artery after the final procedure. CTA, CT angiography. 


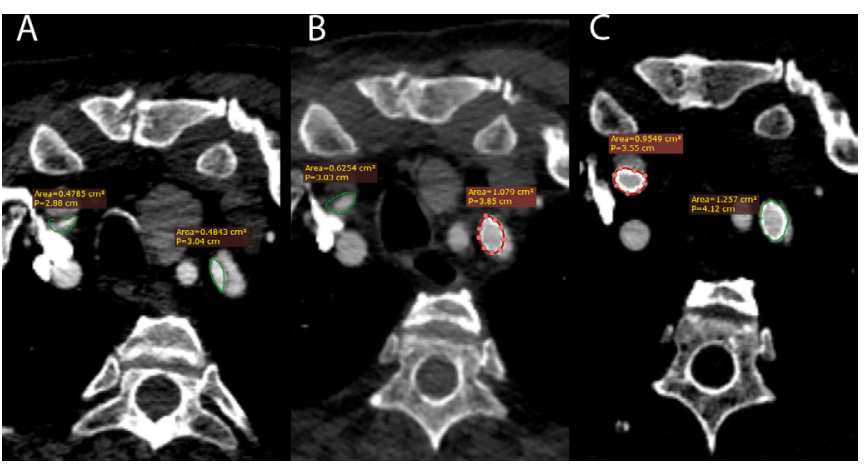

Figure 15 CTA (A) 6 months after the initial surgery and (B) 1 month after the stage 1 procedure and (C) 3 months after the final procedure. Secured and increased true lumen of the left subclavian artery after stage 2 procedure and greatly increased true lumen of the innominate artery after the final procedure. CTA, CT angiography.

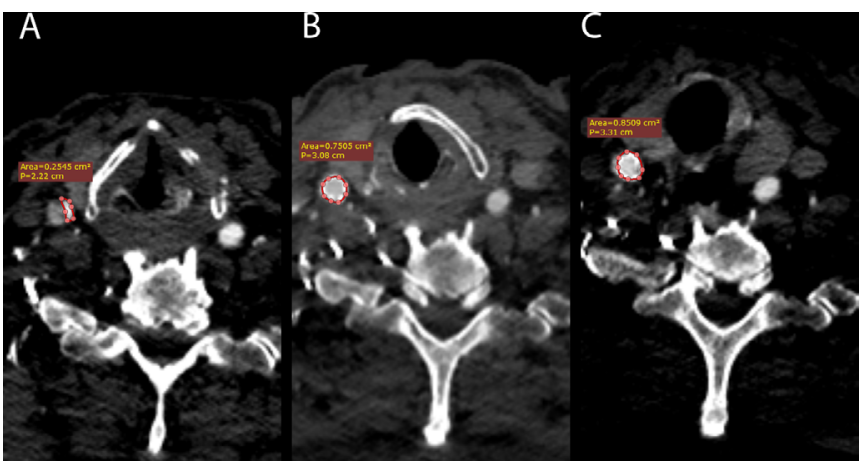

Figure 16 CTA (A) 6 months after the initial surgery, (B) 1 month after the stage 1 procedure and (C) 3 months after the final procedure. Increased true lumen size of the RCCA after stenting. CTA, CT angiography; RCCA, right common carotid artery.

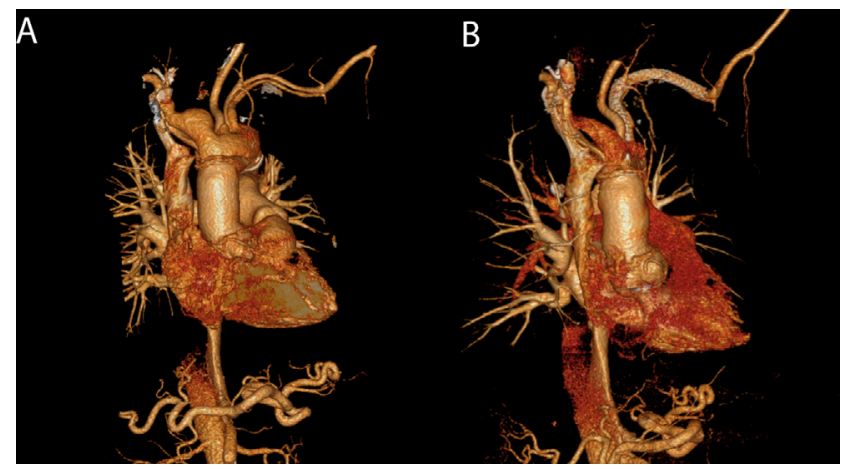

Figure 17 A 3D reconstruction (A) 6 months after the initial surgery and (B) 3 months after the final procedure. The dissection tear on the level of the aortic arch has thrombosed and greatly reduced in size, the true lumen of the innominate artery and the left subclavian artery is secured and increased in size at the expense of the false lumen. 3D, three-dimensional.

of the entry tear. Stent implantation in the true lumen provides extra support and reduces the shear stress on the wall of the vessel. Stenting the left subclavian artery promoted thrombosis and also reduced the possibility of occurrence of a new entry tear in the area of the subclavian artery. Guaranteeing the patency of these arteries was crucial considering the fact that they were engaged in the dissection and the risk of new entry tear was high.

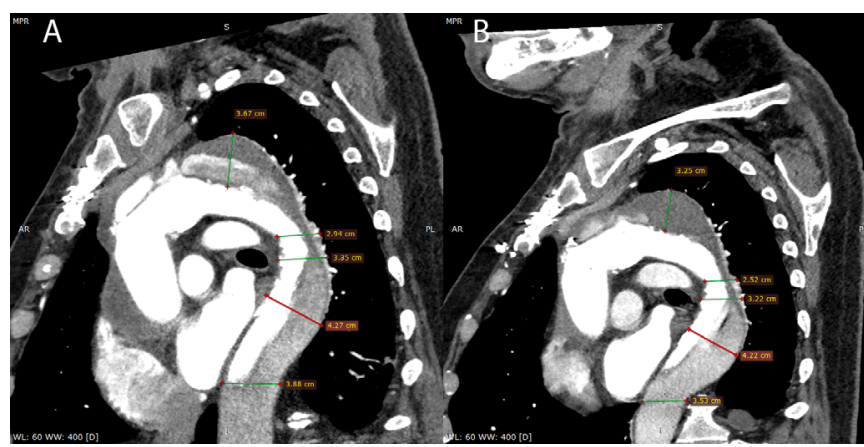

Figure 18 CTA (A) 6 months after the initial surgery and (B) 3 months after the final procedure. Reduced size of the aorta after the procedure and ASD occluder (white arrow) sealing the dissection entry tear. ASD, atrial septal defect; CTA, CT angiography.

Patient's perspective

The CT scan a few months after the surgery showed that the dissection is continuing to grow and I had new concerns. I recovered very slow after the first surgery and I declined a second one and I am thankful that the doctors came up with a solution to solve my problems. The weaknesses on my left side and the frequent headaches disappeared after the procedures.

Learning points

Atrial septal defect occluder device can be used for the closure of dissection entry tear.

- Securing the true lumen in the dissected vessels reduced the shear stress on the vessel wall and reduced the risk of new entry tear.

- Catheter-based minimally invasive approach is a feasible alternative to open surgery even in complex cases when carefully planned and performed by experienced operators.

We decided not to treat the aorta below the diaphragm because of its relatively stable and small size. Isolation of the dissection along the whole aorta was associated with a high risk of complications, including obstruction of visceral arteries. The patient was advised on reducing the risk factors and performing regular follow-up exams.

Contributors The authors are the ones who contributed to the paper.

Funding The authors have not declared a specific grant for this research from any funding agency in the public, commercial or not-for-profit sectors.

Competing interests None declared.

Patient consent for publication Obtained.

Provenance and peer review Not commissioned; externally peer reviewed.

Open access This is an open access article distributed in accordance with the Creative Commons Attribution Non Commercial (CC BY-NC 4.0) license, which permits others to distribute, remix, adapt, build upon this work non-commercially, and license their derivative works on different terms, provided the original work is properly cited and the use is non-commercial. See: http://creativecommons.org/ licenses/by-nc/4.0/.

\section{ORCID iD}

Damyan Boychev Boychev http://orcid.org/0000-0002-7263-8308 


\section{REFERENCES}

1 Sayer D, Bratby M, Brooks M, et al. Aortic morphology following endovascular repair of acute and chronic type B aortic dissection: implications for management. Eur J Vasc Endovasc Surg 2008;36:522-9.

2 Watanabe Y, Shimamura K, Yoshida T, et al. Aortic remodeling as a prognostic factor for late aortic events after thoracic endovascular aortic repair in type $B$ aortic dissection with patent false lumen. J Endovasc Ther 2014;21:517-25.

$3 \mathrm{Kim} \mathrm{T}-\mathrm{H}$, Lee JH, Shim W-H. Embolization of persistent false lumen through reentry tear in a patient who underwent hemiarch replacement operation due to type $A$ dissection. Ann Thorac Surg 2015;99:e43-5.

4 Zierer A, Voeller RK, Hill KE, et al. Aortic enlargement and late reoperation after repair of acute type A aortic dissection. Ann Thorac Surg 2007;84:479-87.

5 Estrera AL, Miller CC, Villa MA, et al. Proximal reoperations after repaired acute type A aortic dissection. Ann Thorac Surg 2007;83:1603-9.

6 Malvindi PG, van Putte BP, Sonker U, et al. Reoperation after acute type A aortic dissection repair: a series of 104 patients. Ann Thorac Surg 2013;95:922-7.

7 Conrad MF, Carvalho S, Ergul E, et al. Late aortic remodeling persists in the stented segment after endovascular repair of acute complicated type B aortic dissection. J Vasc Surg 2015;62:600-5.

8 Hiratzka LF, Bakris GL, Beckman JA, et al. 2010 ACCF/AHA/AATS/ACR/ASA/SCA/ SCAI/SIR/STS/SVM guidelines for the diagnosis and management of patients with thoracic aortic disease: a report of the American College of cardiology Foundation/ American heart association Task force on practice guidelines, American association for thoracic surgery, American College of radiology, American stroke association, society of cardiovascular Anesthesiologists, Society for cardiovascular angiography and interventions, society of interventional radiology, society of thoracic surgeons, and Society for vascular medicine. Circulation 2010;121:e266-369.

9 Falkenberg M, Roos H, Lepore V, et al. Endovascular closure of chronic dissection entries in the aortic arch using the Amplatzer vascular plug II as a sealing button. J Endovasc Ther 2016;23:378-83.

10 Yuan X, Mitsis A, Mozalbat D, et al. Novel endovascular management of proximal type A (DeBakey II) aortic dissection with a patent foramen ovale occluder. J Endovasc Ther 2017:24:809-13.

11 Hussain J, Strumpf R, Ghandforoush A, et al. Transcatheter closure of recurrent aortic pseudoaneurysm previously treated by Amplatzer occluder device. J Vasc Surg 2010;52:196-8.

12 Hata Y, lida O, Asai M, et al. Endovascular entry closure using Amplatzer vascular plug for the aortic dissection in sub-acute phase. J Cardio/ Cases 2018;17:111-5.

13 Kumar PV, Alli O, Bjarnason $\mathrm{H}$, et al. Percutaneous therapeutic approaches to closure of cardiac pseudoaneurysms. Catheter Cardiovasc Interv 2012;80:687-99.

14 Hussain J, Strumpf R, Wheatley G, et al. Percutaneous closure of aortic pseudoaneurysm by Amplatzer occluder device-case series of six patients. Catheter Cardiovasc Interv 2009;73:521-9.

15 Weinberger T, Nabauer M, Massberg S, et al. Interventional closure of a large pseudoaneurysm of the ascending aorta in a patient after lung transplantation. CASE 2019;3:263-6.

16 Kong YH, Song J, Huh J, et al. Outcomes associated with the off-label use of medical devices in congenital heart disease at a single Institute. Korean Circ J 2017;47:509.

17 Mijangos-Vázquez R, El-Sisi A, Sandoval Jones JP, et al. Transcatheter closure of Perimembranous ventricular septal defects using different generations of Amplatzer devices: multicenter experience. J Interv Cardiol 2020;2020:8948249.

Copyright 2021 BMJ Publishing Group. All rights reserved. For permission to reuse any of this content visit https://www.bmj.com/company/products-services/rights-and-licensing/permissions/

BMJ Case Report Fellows may re-use this article for personal use and teaching without any further permission.

Become a Fellow of BMJ Case Reports today and you can:

- Submit as many cases as you like

- Enjoy fast sympathetic peer review and rapid publication of accepted articles

- Access all the published articles

Re-use any of the published material for personal use and teaching without further permission

Customer Service

If you have any further queries about your subscription, please contact our customer services team on +44 (0) 2071111105 or via email at support@bmj.com.

Visit casereports.bmj.com for more articles like this and to become a Fellow 